\title{
ANALISIS PENGENDALIAN PERSEDIAAN BAHAN BAKU KELAPA PADA INDUSTRI TEPUNG KELAPA (Studi Kasus Pada PT. Royal Coconut)
}

\author{
Anggi Lisli Montolalu \\ Celcius Talumingan \\ Eyverson Ruauw
}

\begin{abstract}
The purpose of this research is to analyzed the coconut supply in coconut flour industry (case study at PT. Royal Coconut). This research conducted for three months, February 2016 to April 2016. The data used in this research are prime and secondary data. Prime data obtained by interview with the head manager of the company, the secondary data obtained from company archives, data from BPS, the Department of Industry and Commerce of North Sulawesi, previous literatures and internet. Data processed by EOQ method. The result showed that the raw material supply control policy by PT. Royal coconut not efficient. This shown by the company supply cost higher than the analysis result by used EOQ method with the optimum amount of coconut each order by EOQ method is $384.347,44 \mathrm{~kg}$ with total economic inventory cost Rp. 12.310.648. *ls
\end{abstract}

Key words : Inventory, Material, Economc Order Quantity

\begin{abstract}
ABSTRAK
Penelitian ini bertujuan untuk menganalisis Persediaan Bahan Baku Kelapa Pada Industri Tepung Kelapa (Studi Kasus PT. Royal Coconut). Penelitian ini dilaksanakan selama tiga bulan, sejak bulan februari 2016 sampai bulan april 2016. Data yang digunakan dalam penelitian ini adalah data primer dan data sekunder. Data primer diperoleh melalui wawancara kepada manager perusahaan, sedangkan data sekunder diperoleh dari data yang telah tersusun dalam bentuk dokumen tertulis dari perusahaan, data dari BPS, Dinas Perindustrian dan Perdagangan Sulawesi Utara, literature terdahulu maupun dari internet. Data diolah menggunakan metode EOQ (Econimic Order Quantity). Dari hasil penelitian diketahui bahwa kebijakan pengendalian persediaan bahan baku yang dilakukan PT. Royal Coconut belum efisien, hal ini ditunjukan dengan biaya persediaan perusahaan lebih besar dibanding hasil analisis menggunakan metode EOQ, dengan pemesanan kelapa yang optimal tiap kali pesan menurut metode EOQ adalah $384.347,44 \mathrm{~kg}$ dengan biaya total persediaan ekonomis Rp. 12.310.648.
\end{abstract}

Kata kunci : Persediaan, Bahan Baku, EOQ

\section{PENDAHULUAN}

\section{Latar Belakang}

Provinsi Sulawesi Utara mempunyai potensi sumberdaya alam yang besar pada sektor pertanian. Sektor Pertanian sangat berperan penting terhadap perekonomian di Sulawesi Utara. Perkebunan kelapa mendominasi sektor perkebunan di Sulawesi Utara, dimana luas arealnya mencapai $278.484,10$ hektar dengan total produksi mencapai 284.330,27 ton pada tahun 2014.

Kelapa biasanya diolah dalam beberapa olahan yaitu tepung kelapa, minyak goreng, virgin coconut oil dan masih banyak lagi olahan dari kelapa (Anonim, 2013). Tepung kelapa adalah salah satu olahan dari daging buah kelapa yang saat ini menempati urutan ke-empat dari berbagai produk turunan kelapa yang diekspor ke luar negeri. 
Tabel 1. Luas Areal dan Produksi kelapa Sulut Tahun 2012-2014

\begin{tabular}{lll}
\hline Tahun & Luas $(\mathrm{Ha})$ & $\begin{array}{l}\text { Produksi } \\
\text { (Ton) }\end{array}$ \\
2012 & $250.141,65$ & $272.480,91$ \\
2013 & $278.599,53$ & $282.500,34$ \\
2014 & $278.484,10$ & $284.330,27$ \\
\hline
\end{tabular}

Sumber : BPS ( Sulawesi Utara), 2014

Di Sulawesi Utara terdapat 5 perusahaan yang bergerak dibidang industry tepung kelapa ekspor. Dari lima perusahaan yang ada, PT. Royal Coconut merupakan salah satu perusahaan yang memproduksi tepung kelapa yang dikeringkan (Desiccated Coconut).

EOQ (Economic Order Quantity) adalah jumlah kuantitas barang yang dapat diperoleh dengan biaya yang minimal atau sering dikatakan sebagai jumlah pembelian yang optimal. Metode EOQ (Economic Order Quantity) ini adalah metode yang digunakan untuk mencari titik keseimbangan antara biaya pemesanan dengan biaya penyimpanan agar diperoleh suatu biaya yang minimum.

PT. Royal Coconut dalam kebijakan pengadaan bahan baku selama ini hanya berdasarkan pada pengalaman atau data-data dari masa lalu, hal tersebut akan berpengaruh terhadap total biaya yang dikeluarkan untuk mengadakan persediaan (Ernawati \& Surnasih, 2008). PT. Royal Coconut belum menerapkan manajemen atau analisis dengan menggunakan metode Economic Order Quantity dalam penanganan masalah pengendalian persediaan bahan baku.

\section{Rumusan Masalah}

Berdasarkan uraian di atas maka yang menjadi rumusan masalah dalam penelitian ini, adalah :

a. Berapa banyak bahan baku kelapa optimal yang dibutuhkan oleh PT. Royal Coconut setiap kali pemesanan per periode tahun 2015 ?

b. Berapa besar total biaya persedian bahan baku kelapa menurut kebijakan PT. Royal Coconut dan persediaan minimum dengan metode EOQ per periode tahun 2015 ?

c. Kapan waktu yang tepat untuk melakukan pemesanan ulang (Reorder Cycle) bahan baku kelapa oleh PT. Royal Coconut per periode tahun 2015 ?

\section{Tujuan Penelitian}

Tujuan dari penelitian ini adalah :

1) Untuk menganalisis jumlah pemesanan bahan baku kelapa optimal yang dibutuhkan PT. Royal Coconut per periode tahun 2015.

2) Untuk menganalisis total biaya persediaan bahan baku kelapa PT. Royal Coconut sebelum dan sesudah menggunakan metode EOQ.

3) Untuk menganalisis kapan akan dilakukan pemesanan ulang (Reorder Cycle) bahan baku kelapa oleh PT. Royal Coconut per periode tahun 2015.

\section{Manfaat Penelitian}

Manfaat yang dapat diambil dari penelitian ini adalah sebagai berikut :

1. Bagi Penulis

a. Untuk memenuhi salah satu syarat untuk menyelesaikan studi pada Universitas Sam Ratulangi Fakultas Pertanian Jurusan Sosial Ekonomi Program Studi Agribisnis.

b. Menerapkam ilmu-ilmu yamg dipelajari selama perkulihan dalam hal ini meningkatkan pengetahuan megenai system persedian bahan baku.

2. Bagi perusahaan, diharapkan dengan adanya penelitian ini dapat menjadi bahan pertimbangan bagi perusahaan dalam hal pengambilan keputusan yang berhubungan dengan persediaan bahan baku.

3. Bagi pembaca, dapat menjadi sumber informasi dan masukan yang dapat digunakan dalam penelitian selanjutnya.

\section{METODOLOGI PENELITIAN}

\section{Lokasi dan Waktu Penelitian}

Penelitian dilakukan di PT. Royal Coconut yang terletak di desa Kawangkoan, Kec. Kalawat Kab. Minahasa Utara. Penelitian ini akan dilaksanakan selama 3 bulan dari persiapan sampai penyusunan laporan, yaitu pada bulan Februari 2016 sampai bulan april 2016. 


\section{Jenis dan Metode Pengumpulan Data}

Data yang digunakan dalam penelitian ini adalah data primer dan data sekunder. Data primer diperoleh melalui wawancara langsung dengan menggunakan kuisioner kepada manager perusahaan, sedangkan data sekunder diperoleh dari data yang telah tersusun dalam bentuk dokumen tertulis dari perusahaan, data dari BPS, Dinas Perindustrian dan Perdagangan Sulawesi Utara, literature terdahulu maupun dari internet.

\section{Konsepsi Pengukuran Variabel}

1. Jumlah kebutuhan bahan baku (Kg/Bulan)

2. Biaya pemesanan (Rp), adalah biaya yang dikeluarkan sehubungan dengan pemesanan bahan baku, antara lain :
a. Biaya pengadaan bahan baku
b. Biaya Angkutan
c. Biaya Buruh Angkut Pembongkaran

3. Biaya penyimpanan (Rp), adalah biaya yang dikeluarkan sehubungan dengan penyimpana bahan baku, antara lain :
a. Biaya Penerangan
b. Biaya Penanganan Persediaan

4. Biaya Total Persediaan (Total Inventory Cost), merupakan penjumlahan total biaya pemesanan dan total biaya penyimpanan bahan baku (Rp)

5. Pemesanan Ulang (Reoder Cycle), saat atau waktu tertentu perusahaan harus mengadakan pemesanan bahan dasar kembali, sehingga datangnya pesanan tersebut tepat dengan habisnya bahan dasar yang dibeli, khususnya dengan metode $E O Q$.

\section{Metode Analisis Data}

Analisis data yang digunakan dalam penelitian ini adalah menggunakan metode EOQ (Economic Order Quantity).

Keterangan :

$$
\mathrm{EOQ}=\sqrt{\frac{2 D s}{h}}
$$
D : Kebutuhan dalam suatu periode perencanaan $(\mathrm{Kg})$
$\mathrm{s}$ : Biaya yang dikeluarkan setiap kali

pemesanan $(\mathrm{Rp})$

$\mathrm{h}$ : Biaya penyimpanan setiap unit persediaan (Rp)

$$
\text { Biaya Simpan }=\left(\frac{Q}{2}\right) h
$$

Keterangan :

Q : Jumlah bahan baku yang di pesan setiap kali pemesanan $(\mathrm{Kg})$

$\mathrm{h}$ : Biaya penyimpanan $(\mathrm{Rp})$

Keterangan :

$$
\text { Biaya Pesan }=\left(\frac{D}{Q}\right) s
$$

D : Kebutuhan dalam suatu periode perencanaan $(\mathrm{Kg})$

Q : Jumlah bahan baku yang di pesan setiap kali pemesanan $(\mathrm{Kg})$

$\mathrm{s}$ : Biaya yang dikeluarkan setiap kali pemesanan $(\mathrm{Rp})$

Total Biaya Persediaan $($ TIC $)=$ BP + BS

Keterangan :

BP : Biaya Pesan (Rp)

BS : Biaya Simpan (Rp)

$$
\text { Pemesanan Ulang : } \mathbf{P}=\frac{\mathbf{D}}{\mathbf{Q}}
$$

Keterangan :

$\mathrm{P}$ : Siklus Pesan Ulang

D : Kebutuhan dalam suatu periode perencanaan $(\mathrm{Kg})$

Q : Jumlah bahan baku yang di pesan setiap kali pemesanan $(\mathrm{Kg})$

\section{Periode Waktu Setiap Kali Pemesanan}

Keterangan :

$$
\text { Ulang : } \mathbf{Y}=\frac{W}{P}
$$

Y : Periode Waktu Perencanan (Hari)

$\mathrm{P}$ : Siklus Pesanan Ulang

W: Periode Waktu Setiap Siklus Pesanan

Ulang (Hari)

Tingkat Pemakaian Saat Pemesanan Ulang :

$$
\Delta \frac{\boldsymbol{D}}{\Delta \boldsymbol{W}} \Delta \frac{\boldsymbol{Q}}{\Delta \boldsymbol{Y}}
$$

Keterangan :

D : Kebutuhan Dalam suatu periode perencanaan $(\mathrm{Kg})$

$\Delta \mathrm{W}$ : Periode Waktu Setiap Siklus 
Pesanan Ulang (Hari)

$\mathrm{Q}$ : Jumlah pemesanan persediaan $(\mathrm{Kg})$

$\Delta Y$ : Periode Waktu Perencanan (Hari)

\section{HASIL DAN PEMBAHASAN}

\section{Profil Perusahaan}

PT. Royal Coconut berdiri pada tahun 2005 dan mulai produksi pada tahun 2007. PT. Royal Coconut merupakan salah satu perusahaan yang bergerak dibidang industry tepung kelapa ekspor di Sulawesi Utara. Produk yang dihasilkan PT. Royal Coconut adalah tepung kelapa yang di keringkan (Desiccated Coconut).

PT. Royal Coconut mempunyai 352 karyawan, dengan jam kerja yang terdiri dari tiga shift, shift I jam 06.00 - 15.00, shift II jam 14.00 - 24.00 dan shift III jam $23.00-$ 06.00. Perusahaan berlokasi di desa Kawangkoan, Kecamatan Kalawat Kab. Minahasa Utara.

\section{Pengendalian Persediaan Bahan Baku}

Syarat kerja sama yang dilakukan antara PT. Royal Coconut dengan para pemasok yaitu kelapa yang dibeli perusahaan adalah kelapa dalam yang ber-umur 2,5 bulan yang layak dibuat tepung. Bahan baku biasanya tiba 1-3 hari setelah pemesanan, tapi umumnya langsung dibawah. Bahan baku sampai diperusahaan, kemudian dilakukan pemeriksaan kuantitas dan kualitas bahan baku, setelah itu dimasukan ke dalam gudang.

Gudang Kelapa terbagi atas tiga bilik yang berfungsi untuk memisahkan kelapa yang lebih dulu masuk ke gudang untuk di diproduksi lebih dulu, karena mengingat bahan baku yang telah disimpan hanya memiliki jangka waktu kerusakan yaitu 3-4 hari, namun kerusakan biasanya hanya terjadi apabila ada kerusakan mesin.

Pemasok bahan baku kelapa di PT. Royal Coconut adalah supplier tetap sebanyak 37 orang, sebagian besar berasal dari Minahasa Utara yaitu sebesar $80 \%$ dan sisanya berasal dari Minahasa Selatan dan Minahasa Tenggara.

\section{Kapasitas Produksi}

Kapasitas produksi di PT. Royal Coconut bisa mencapai $90.000 \mathrm{~kg}$ kelapa dalam satu kali produksi dengan lama produksi 25 jam apabila produksi normal tidak ada kerusakan mesin maupun kekurangan tenaga kerja. Pada tahun 2015 produksi tertinggi mencapai $90.000 \mathrm{~kg}$ dan produksi terendah sebesar $50.000 \mathrm{~kg}$.

\section{Analisis Persediaan Metode EOQ}

Permintaan, Pembelian dan Penggunaan Bahan Baku. Untuk memenuhi permintaan tepung kelapa, kebutuhan bahan baku PT. Royal Coconut per hari sebesar $90.000 \mathrm{~kg}$. Pembelian terendah terjadi pada bulan januari, pada bulan tersebut perusahaan melakukan pembelian sebesar $644.640 \mathrm{~kg}$ bahan baku. Sedangkan jumlah pembelian terbesar terjadi bulan juni, pada bulan tersebut perusahaan melakukan pembelian bahan baku sebesar $1.742 .744 \mathrm{~kg}$. Rata-rata penggunaan bahan baku pada tahun 2015 sebesar $1.347 .349 \mathrm{~kg}$, dibandingkan dengan pembelian bahan baku yang rata-rata per bulannya mencapai 1.386.024 kg. Hal ini menunjukan bahwa tingkat pembelian pada tahun 2015 lebih tinggi dari pada tingkat penggunaan bahan bakunya. Perusahaan melakukan penyimpanan bahan baku dengan alasan persediaan dalam proses produksi dan untuk mengantisipasi adanya kelangkaan bahan baku.

\section{Biaya Pemesanan}

Untuk biaya yang dikeluarkan perusahaan pada setiap kali pemesanan adalah sebesar Rp. 146.323,31 yang diperoleh dari total biaya pemesanan yang dikeluarkan perusahaan pada tahun 2015 dibagi dengan frekuensi pemesanan yang dilakukan pada tahun tahun 2015 yaitu 4.135 kali.

\section{Biaya Penyimpanan}

Untuk biaya penyimpanan per $\mathrm{kg}$ kelapa yang dikeluarkan oleh PT. Royal Coconut adalah Rp.32,03. Biaya ini didapat dari pembagian antara total biaya penyimpanan dengan hasil rata-rata pembelian kelapa tahun 2015 sebesar $1.386 .024 \mathrm{~kg}$. 
Tabel 2. Biaya Pemesanan Bahan Baku Kelapa PT. Royal Coconut Tahun 2015

Jenis Biaya

Biaya Pengadaan Bahan Baku

Biaya Angkutan Bahan Baku

Biaya Buruh Angkut dan Bongkar Kelapa
(Rp)

537.457 .940

29.767.315

37.821 .623

\begin{tabular}{|c|c|}
\hline Jumlah & \\
\hline Sumber : PT. I & 2016 \\
\hline $\begin{array}{r}\text { Tabel 3. Biay } \\
\text { Kela } \\
2015 \\
\end{array}$ & $\begin{array}{l}\text { an Bahan Baku } \\
\text { Coconut Tahun }\end{array}$ \\
\hline Jenis Biaya & (Rp) \\
\hline Biaya & 2.400 .000 \\
\hline Penerangan & \\
\hline $\begin{array}{l}\text { Penanganan } \\
\text { Persediaan }\end{array}$ & 42.000 .000 \\
\hline Jumlah & 44.400 .000 \\
\hline
\end{tabular}

Sumber :PT. Royal Coconut, 2016

Untuk biaya yang dikeluarkan perusahaan pada setiap kali pemesanan adalah sebesar Rp. 146.323,31 yang diperoleh dari total biaya pemesanan yang dikeluarkan perusahaan pada tahun 2015 dibagi dengan frekuensi pemesanan yang dilakukan pada tahun tahun 2015 yaitu 4.135 kali.

Tabel 4. Penggunaan Bahan Baku Kelapa, Biaya Pemesanan dan Biaya Penyimpanan di PT. Royal Coconut tahun 2015

\begin{tabular}{lr}
\hline \multicolumn{1}{c}{ Uraian } & \multicolumn{1}{c}{$\mathbf{2 0 1 5}$} \\
\hline Kuantitas (Kg) & 16.168 .190 \\
Biaya Pemesanan (Rp) & $146.323,31$ \\
Biaya Penyimpann (Rp) & 32,03 \\
\hline
\end{tabular}

Sumber : Data Olahan, 2016

Dari Tabel 5 dapat disimpulkan bahwa pemesanan kelapa yang ekonomis adalah $384.347,44 \mathrm{~kg}$ dengan frekuensi pemesanan bahan baku sebanyak 42 kali dengan periode waktu pemesanan ulang adalah 7 hari dan waktu pemesanan ulang (Reorder Point) pada saat persediaan tinggal $164.720,33 \mathrm{~kg}$ dengan biaya total persediaan ekonomis sebesar Rp. 12.310.648.

Tabel 5. Hasil Perhitungan EOQ, Reorder Cycle dan Biaya Total Persediaan Bahan Baku Kelapa pada PT. Royal Coconut tahun 2015

\begin{tabular}{lr}
\multicolumn{1}{c}{ Uraian } & 2015 \\
EOQ $(\mathrm{Kg})$ & 384.347, \\
& 44 \\
Pemesanan Ulang & \\
(Kali/Pemesanan) & 42 \\
Periode Waktu & \\
Pemesanan Ulang (Hari) & 7
\end{tabular}

Reorder Point $(\mathrm{Kg}) \quad 164.720$,

Biaya Total Persediaan

Ekonomis (Rp) $\quad 12.310 .6$ 48

Sumber : Data Olahan, 2016

\section{KESIMPULAN DAN SARAN}

\section{Kesimpulan}

Berdasarkan hasil penelitian dan analisis data pada bab sebelumnya, maka dapat disimpulkan bahwa kebijakan pengendalian persediaan bahan baku yang dilakukan PT. Royal Coconut belum efisien, dapat dikemukakan kesimpulan sebagai berikut :

1. Pembelian bahan baku kelapa optimal setiap kali pemesanan menurut metode EOQ adalah $384.347,44 \mathrm{~kg}$.

2. Total biaya persediaan optimal menurut metode EOQ adalah Rp. 12.310.648 sedangkan menurut kebijakan perusahaan sebesar Rp. 648.202.475.

3. Frekuensi pemesanan bahan baku menurut kebijakan perusahaan sebesar 4.135 kali sedangkan menurut metode $E O Q$ sebanyak 42 kali dengan periode waktu pemesanan ulang adalah 7 hari dan titik pemesanan ulang (Reorder Point) pada saat persediaan tinggal $164.720,33 \mathrm{~kg}$. 


\section{Saran}

Setelah mengadakan perhitungan dan menganalisis data tentang pengadaan persediaan bahan baku kelapa pada PT. Royal Coconut, maka penulis mengajukan saran yang dapat dijadikan bahan pertimbangan dalam kebijakan pengadaan bahan baku. Adapun saran-saran sebagai berikut :

1. Perusahaan sebaiknya menggunakan metode $E O Q$ dalam kebijakan pengadaan bahan baku, karena dengan menggunakan metode $E O Q$ perusahaan akan mendapatkan kuantitas pembelian bahan baku yang optimal dengan biaya yang minimum dibandingkan kebijakan perusahaan sebelumnya. Perusahaan perlu mengkaji kembali metode pengendalian yang diterapkan selama ini, karena berdasarkan hasil pengolahan dengan metode $E O Q$ yang digunakan peneliti, total biaya persediaan masih dapat diminimalkan.

2. Perusahaan perlu mengkaji kembali metode pengendalian yang diterapkan selama ini, karena berdasarkan hasil pengolahan dengan metode EOQ yang digunakan peneliti, total biaya persediaan masih dapat diminimalkan.

\section{DAFTAR PUSTAKA}

Anonimous,2013. Penelitian Pabrik Tepung Kelapa.

http://agussupu.wordpress.com/tag/pene litian-pabrik-tepung-kelapa (diakses Februari 2015).

Asrori, H., 2010. Analisis Pengendalian Persediaan Bahan Baku Kayu Sengon PT. Abhirama Kresna Dengan Metode EOQ (skripsi).Program Studi Manajemen Industri Fakultas Ekonomi Universitas Sebelas Maret Surakarta.

Badan Pusat Statistik, 2014. Data Luas Areal Tanaman Perkebunan di Sulut. Manado.

Dinas Perindustrian \& Perdagangan Sulawesi Utara, 2015. Daftar Eksportir Tepung Kelapa Di Sulut. Manado.

Ernawati, Y., \& Surnasih. (2008). Sistem Pengendalian Persediaan Model Probabilistik dengan "Back Order Policy." Jurnal Matematika, 11(2), 8793.
Fahmi, 2012. Manajemen Produksi dan Operasi. Penerbit: Alfabeta, Bandung.

Handoko, T,H., 2015. Dasar-Dasar Manajemen Produksi dan Operasi. BPFE, Yogyakarta.

Hartini, S., \& Larasati, I., (2009). Pendekatan dynamic inventory dengan mempertimbangkan ketidakpastian permintaan, yield, dan leadtime.J@TI UNDIP, IV(3), 202-211.

Heizer, J., Barry, R., 2001. Prinsip - prinsip Manajemen Operasi. Salemba Empat. Jakarta.

Herjanto, Eddy. 2008. Manajemen Operasi. Edisi Ketiga. PT. Raja Grasindo Persada. Jakarta.

Kusuma, H., 2009. Manajemen Produksi:Perencanaan dan Pengendalian Produksi. Edisi 4. Yogyakarta: Penerbit Andi.

Rangkuti, F., 2004. Manajemen Persediaan Aplikasi di Bidang Bisnis. Jakarta: Penerbit Erlangga.

Ruauw, E., (2011) Pengendalian Persediaan Bahan Baku Pada Usaha Grenda Bakery Lianli, Manado. Jurnal ASE

Simbar, M., Skripsi Analisis Pengendalian Persediaan Bahan Baku Kayu Cempaka pada Industri Mebel dengan menggunkan Metode EOQ (Studi Kasus Pada UD. Batu Zaman), Manado 2014

Suhartanti, R., Skripsi Analisis Pengendalian Persedian Bahan Baku Minuman Bandrek Pada CV. Cihanjuang Inti Teknik, Jakarta 2009

Sutarman. (2003). Perencanaan Persediaan Bahan Baku dengan Model Backorder. FTI Universitas Pasundan Bandung.

Tatuh, D., (2015) Analisis Pengelolaan Persediaan Beras Di PT. Semarak Kota Bitung, Manado. Jurnal.

Veronica, M., Skripsi Analisis Pengendalian Persedian Bahan Baku Beras Dengan Metode Economic Order Quantity (EOQ) Multi Produk Guna Meminimumkan Biaya Pada CV. Lumbung Tani Makmur di Banyuwangi, Jember 2013

Yamit, J., 2007. Manajemen Kuantitatif Untuk Bisnis (Operation Reseacrch). BPFE, Yogyakarta. 